Article

\title{
The Influence of Dynamic Tissue Properties on HIFU Hyperthermia: A Numerical Simulation Study
}

\author{
Qiaolai Tan ${ }^{1,2}$, Xiao Zou ${ }^{1}$, Yajun Ding ${ }^{3}$, Xinmin Zhao ${ }^{1}$ and Shengyou Qian ${ }^{1, *}$ \\ 1 School of Physics and Electronics, Hunan Normal University, Changsha 410081, China; \\ tanq11981@smail.hunnu.edu.cn (Q.T.); shawner@hunnu.edu.cn (X.Z.); 470241651@hunnu.edu.cn (X.Z.) \\ 2 School of Electronic Information and Electrical Engineering, Xiangnan University, Chenzhou 423000, China \\ 3 College of Information Science and Engineering, Hunan Normal University, Changsha 410081, China; \\ yajunding@hunnu.edu.cn \\ * Correspondence: shyqian@hunnu.edu.cn
}

Received: 2 September 2018; Accepted: 10 October 2018; Published: 16 October 2018

check for updates

\begin{abstract}
Accurate temperature and thermal dose prediction are crucial to high-intensity focused ultrasound (HIFU) hyperthermia, which has been used successfully for the non-invasive treatment of solid tumors. For the conventional method of prediction, the tissue properties are usually set as constants. However, the temperature rise induced by HIFU irradiation in tissues will cause changes in the tissue properties that in turn affect the acoustic and temperature field. Herein, an acoustic-thermal coupling model is presented to predict the temperature and thermal damage zone in tissue in terms of the Westervelt equation and Pennes bioheat transfer equation, and the individual influence of each dynamic tissue property and the joint effect of all of the dynamic tissue properties are studied. The simulation results show that the dynamic acoustic absorption coefficient has the greatest influence on the temperature and thermal damage zone among all of the individual dynamic tissue properties. In addition, compared with the conventional method, the dynamic acoustic absorption coefficient leads to a higher focal temperature and a larger thermal damage zone; on the contrary, the dynamic blood perfusion leads to a lower focal temperature and a smaller thermal damage zone. Moreover, the conventional method underestimates the focal temperature and the thermal damage zone, compared with the simulation that was performed using all of the dynamic tissue properties. The results of this study will be helpful to guide the doctors to develop more accurate clinical protocols for HIFU treatment planning.
\end{abstract}

Keywords: HIFU; dynamic tissue property; Westervelt equation; thermal damage zone

\section{Introduction}

Cancer is one of the serious diseases that threatens the life and health of humans. According to cancer statistics released by the National Cancer Center of China, 3.804 million new cancer cases were diagnosed and 2.296 million cancer deaths were reported in 2014 [1]. Traditional therapies for cancer include surgery resection, chemotherapy, and radiotherapy. In recent years, other alternative therapies such as microwave ablation, laser ablation, cryoablation, and high-intensity focused ultrasound (HIFU) hyperthermia also have developed rapidly [2,3]. HIFU therapy is a non-invasive technology in which an ultrasound beam carries sufficient energy, and the energy is focused onto the target area to cause a local temperature rise, which is sufficiently high to make the lesion tissue undergo coagulative necrosis without causing damage to the overlaying or surrounding tissue $[4,5]$. It has many advantages such as non-invasive, non-contact, non-ionization, and low cost [6,7], and has been successfully used in clinics to treat solid malignant tumors, including cancers of the prostate, liver, kidney, breast, and pancreas [8]. The clinical success of HIFU hyperthermia depends on the accurate thermal dose at the lesion location. 
Unfortunately, it is difficult to accurately measure the thermal dose at a depth of the tissue in most clinical situations. Instead, a numerical simulation method is usually used to predict the transient temperature profiles and thermal dose to assess the thermal damage that will occur in tissue during HIFU ablation [9].

In the conventional method, the numerical simulation of HIFU hyperthermia is usually based on the acoustic model Westervelt equation and the thermal model Pennes bioheat transfer equation, and the tissue properties are set as constants. However, that the tissue properties varied with temperature had been observed in several experimental studies [10-13]. Moreover, the temperature-dependent tissue properties in turn affect the acoustic field and temperature field. Several researchers have considered some temperature-dependent tissue properties to perform the numerical study of HIFU hyperthermia [9,14,15]. For example, Hallaj [14] studied the effect of dynamic sound speed in the liver with and without a fat layer undergoing HIFU surgery. Christopher [15] examined the importance of the thermal lens effect with a phased array transducer in the liver with the fat layer when considering dynamic sound speed and a dynamic acoustic absorption coefficient in the HIFU hyperthermia study using three-dimensional model. Guntur [9] studied the influence of temperature-dependent thermal parameters on temperature during HIFU irradiation by comparing the conventional prediction of temperature and the thermal damage zone with that for different thermal parameters (i.e., specific heat capacity and thermal conductivity) at the given temperatures. However, only one or two dynamic tissue properties were considered in the above studies; to our knowledge, other dynamic tissue properties such as density and blood perfusion have never been considered. Furthermore, the joint effect of two dynamic tissue properties was investigated in the above studies, but the individual influence of each tissue property on HIFU hyperthermia is still unclear. Therefore, we first study the evolutions of the acoustic and temperature fields with each dynamic tissue property independently, and clarify the physical significance of each tissue property. In addition, we develop an acoustic-thermal model to evaluate the joint effect of all of the dynamic tissue properties on temperature distribution and thermal damage, including sound speed, acoustic absorption coefficient, non-linearity parameter, specific heat capacity, thermal conductivity, density, and blood perfusion. The results provide a more accurate prediction of temperature distribution and thermal damage, gaining insight into the complex dynamic processes during HIFU hyperthermia, which are useful for doctors making treatment planning.

\section{Theory}

\subsection{Acoustic Model for Ultrasound Wave Propagation}

Generally, the Westervelt equation $[16,17]$ is used to model the ultrasound wave propagation in the thermoviscous medium:

$$
\left(\nabla^{2}-\frac{1}{c^{2}} \frac{\partial^{2}}{\partial t^{2}}\right) p+\frac{\delta}{c^{4}} \frac{\partial^{3} p}{\partial t^{3}}+\frac{\beta}{\rho c^{4}} \frac{\partial^{2} p^{2}}{\partial t^{2}}=0
$$

where $\nabla^{2}, p, c, t$ are the Laplace operator, acoustic pressure, sound speed, and time, respectively; the non-linearity coefficient $\beta$ is related to the non-linearity parameter $B / A$ by $\beta=1+(B / 2 A)$; and $\delta=2 \alpha c^{3} / \omega^{2}$ is the acoustic diffusivity accounting for the thermoviscous effect in the fluid [18], where $\omega$ is the acoustic angular frequency and $\alpha$ is the acoustic absorption coefficient.

The acoustic field is computed by Westervelt equation in two-dimensional (2D) cylindrical coordinate using the finite-difference time-domain (FDTD). The $z$-axis is the acoustic axis of the ultrasonic transducer, and $r$ is the radial coordinate measured from the $z$-axis. The excitation of the ultrasonic transducer is:

$$
p(t)=p_{0} \sin (\omega t)
$$

where $p_{0}$ is the amplitude of acoustic pressure on the ultrasonic transducer. 
An absorbing boundary condition $(\mathrm{ABC})$ is imposed at the edge of the computation domain to prevent or minimize the reflection from the edges of the domain, and a first-order Mur's absorption boundary condition is employed [19]:

$$
\frac{\partial p}{\partial x}-\frac{1}{c} \frac{\partial p}{\partial t}=0
$$

where $x$ denotes $z$ or $r$ in their own ultrasonic wave propagation direction.

\subsection{Thermal Energy Model for Tissue Heating}

The transfer of heat in the tissue under HIFU irradiation is modeled using the Pennes bioheat transfer equation [20]:

$$
\rho_{t} C_{t} \frac{\partial T}{\partial t}=k \nabla^{2} T-W_{b} C_{b}\left(T-T_{a}\right)+Q_{e x t}
$$

where $C_{t}$ and $\rho_{t}$ are the specific heat and density of tissue, respectively; $C_{b}, W_{b}$, and $T_{a}$ are the specific heat, perfusion rate, and ambient temperature of blood, respectively. $Q_{\text {ext }}$ is the ultrasound heat deposition term, which can be calculated by employing the time averaged over one acoustic period by numerical integration [14]:

$$
Q_{e x t}=\frac{2 \alpha}{\rho c \omega^{2}}\left\langle\left(\frac{\partial p}{\partial t}\right)^{2}\right\rangle
$$

To evaluate the performance of the HIFU treatment, thermal dose is usually used to estimate the tissue damage. The thermal dose depends on the final time $t_{f}$ and temperature level $T$, which was developed by Sapareto and Dewey [21]:

$$
t_{43}=\int_{0}^{t_{f}} R^{(T-43)} d t \approx \sum_{0}^{t_{f}} R^{(T-43)} \Delta t
$$

where $t_{43}$ is the thermal dose equivalent time at $43{ }^{\circ} \mathrm{C}$. $R=2$ if $T \geq 43^{\circ} \mathrm{C}$, and $R=4$ if $37^{\circ} \mathrm{C}<T<$ $43^{\circ} \mathrm{C}$. The threshold value of an isothermal dose value of $240 \mathrm{~min}$ at $43^{\circ} \mathrm{C}$ was usually selected to predict the size of the thermal lesion region.

Another way to quantify the tissue thermal damage is to use the Arrhenius equation [22]:

$$
\Omega=\int_{0}^{t_{f}} A \exp \left(\frac{-E_{a}}{R_{a} T}\right) d t
$$

where $A, E_{a}$, and $R_{a}$ are the frequency factor, activation energy, and universal gas constant, respectively. For liver thermal damage, $A=9.4 \times 10^{104} \mathrm{~s}^{-1}, E_{a}=6.68 \times 10^{5} \mathrm{~J} \mathrm{~mol}^{-1}$, and $R_{a}=$ $8.31 \mathrm{~J} \mathrm{~mol}^{-1} \mathrm{~K}^{-1}$ [23]. The undamaged fraction of the tissue and the damaged fraction can be estimated by $f_{u}=\exp (-\Omega)$ and $f_{d}=1-f_{u}$, respectively [24].

\subsection{Dynamic Tissue Propertiesc}

The acoustic and thermal parameters of tissue were strongly dependent on tissue temperature, and many experimental data had been obtained [10-13]. The data for acoustic absorption coefficient and sound speed were derived from measurements in liver tissue by Damianou [10] and Bamber [11], respectively. The polynomials to fit the acoustic absorption coefficient and sound speed in liver tissue to experimental data are [15]:

$$
\begin{gathered}
\alpha_{\text {liver }}=5.5367-2.9950 \times 10^{-1} \mathrm{~T}+3.3357 \times 10^{-2} \mathrm{~T}^{2}-1.6058 \times 10^{-3} \mathrm{~T}^{3}+3.4382 \times 10^{-5} \mathrm{~T}^{4} \\
-3.2486 \times 10^{-7} \mathrm{~T}^{5}+1.1181 \times 10^{-9} \mathrm{~T}^{6} \quad 30^{\circ} \mathrm{C} \leq \mathrm{T} \leq 90^{\circ} \mathrm{C} .
\end{gathered}
$$




$$
\begin{gathered}
c_{\text {liver }}=1529.3+1.6856 \mathrm{~T}+6.1131 \times 10^{-2} \mathrm{~T}^{2}-2.2967 \times 10^{-3} \mathrm{~T}^{3} \\
+2.2657 \times 10^{-5} \mathrm{~T}^{4}-7.1795 \times 10^{-8} \mathrm{~T}^{5} \quad 30^{\circ} \mathrm{C} \leq \mathrm{T} \leq 90^{\circ} \mathrm{C}
\end{gathered}
$$

In this study, the experimental data for the change in the non-linearity parameter with temperature in the liver tissue are derived from measurements by Choi [12], and the experimental data for the changes in the specific heat capacity, thermal conductivity, and density with temperature in liver tissue are derived from measurements by Guntur [13]. We obtain the expressions of the temperature-dependent non-linearity parameter, specific heat capacity, thermal conductivity, and density respectively by the least squares polynomial fitting their experimental data in liver tissue:

$$
\begin{aligned}
& \left(\frac{B}{A}\right)_{\text {liver }}=6.68-0.41448 \mathrm{~T}+0.03364 \mathrm{~T}^{2}-0.00101 \mathrm{~T}^{3}+1.34407 \times 10^{-5} \mathrm{~T}^{4} \\
& -6.35346 \times 10^{-8} \mathrm{~T}^{5} \quad 30^{\circ} \mathrm{C} \leq \mathrm{T} \leq 75^{\circ} \mathrm{C} \\
& C_{\text {liver }}=3600+53.55552 \mathrm{~T}-3.96009 \mathrm{~T}^{2}+0.10084 \mathrm{~T}^{3}-0.00106 \mathrm{~T}^{4} \\
& +4.01666 \times 10^{-6} T^{5} \quad 20^{\circ} \mathrm{C} \leq T \leq 90^{\circ} \mathrm{C} \\
& K_{\text {liver }}=0.84691-0.02094 \mathrm{~T}+3.89971 \times 10^{-4} T^{2}-5.47451 \times 10^{-7} T^{3} \\
& -4.14455 \times 10^{-8} T^{4}+2.97188 \times 10^{-10} T^{5} \quad 20{ }^{\circ} \mathrm{C} \leq \mathrm{T} \leq 90^{\circ} \mathrm{C} \\
& \rho_{\text {liver }}=1084.09352-2.97434 \mathrm{~T}+0.0042 T^{2}+0.00293 T^{3}-6.14447 \times 10^{-5} T^{4} \\
& +3.33019 \times 10^{-7} T^{5} \quad 20^{\circ} \mathrm{C} \leq \mathrm{T} \leq 90^{\circ} \mathrm{C}
\end{aligned}
$$

The polynomials above are shown in Figure 1, which have the validity in their own temperature range. In this study, their use is also strictly restricted to their respective temperature ranges.
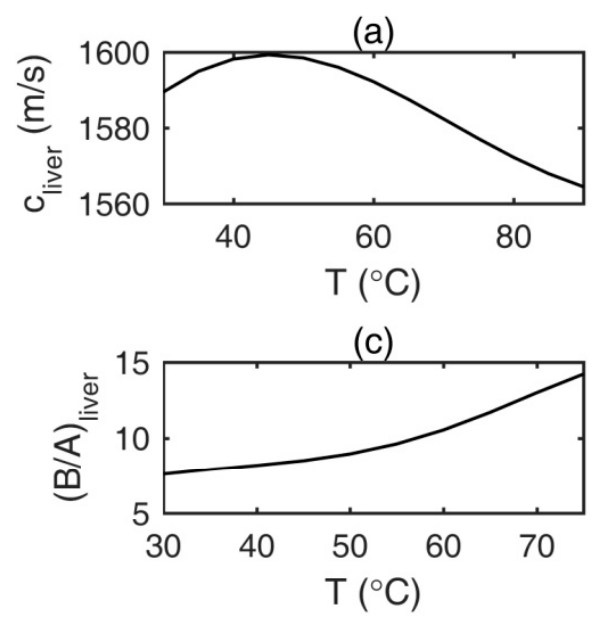

(e)

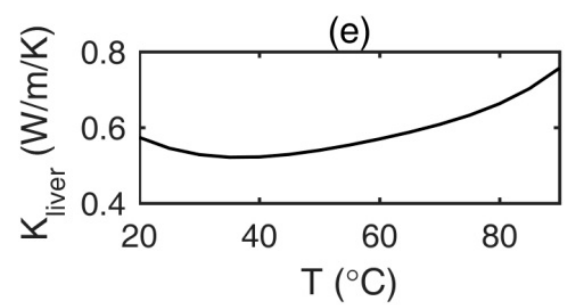

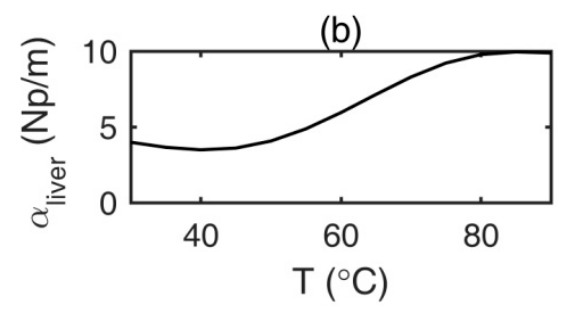

(d)
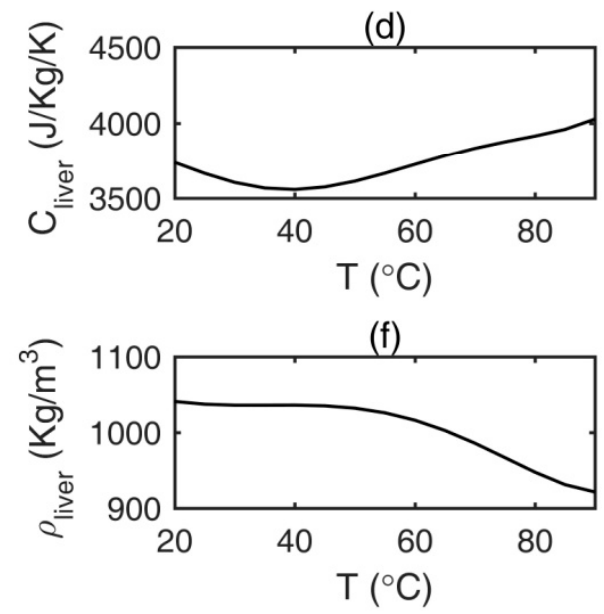

Figure 1. Temperature-dependent tissue properties in liver tissue.

The variation of the blood perfusion rate with temperature and thermal damage can be described by:

$$
W_{b, l i v e r}(T, \Omega)=W_{b, 0} f_{T} f_{u}
$$


where $W_{b, 0}$ is the constitutive blood perfusion rate, $18.2 \mathrm{Kg} \mathrm{m}^{-3} \mathrm{~s}^{-1}$ for liver, and $f_{T}$ is a dimensionless function that accounts for vessel dilation at slightly elevated temperatures, which can be approximated as [23,24]:

$$
f_{T}=\left\{\begin{array}{c}
4+0.6(T-42) 37^{\circ} \mathrm{C} \leq T \leq 42{ }^{\circ} \mathrm{C} \\
4 T \geq 42{ }^{\circ} \mathrm{C}
\end{array}\right.
$$

The blood perfusion rate increases as the temperature rises, but as tissue coagulation develops, it is decreased to zero due to the factor of thermal damage [25].

In order to study the effects of dynamic tissue properties on HIFU hyperthermia, we compare the simulation using dynamic tissue properties with the conventional method using tissue properties with constant values. In this study, the constant values of tissue properties were obtained from the values of the above fitting formula at $37^{\circ} \mathrm{C}$. The values of the acoustic and thermal parameters are listed in Tables 1 and 2, respectively.

Table 1. Values of acoustic parameters in this study $\left(37^{\circ} \mathrm{C}\right)$.

\begin{tabular}{ccccc}
\hline Material & $\boldsymbol{\rho}\left(\mathrm{Kg} \mathrm{m}^{-3}\right)$ & $\boldsymbol{c}\left(\mathrm{m} \mathrm{s}^{-1}\right)$ & $\left.\boldsymbol{\alpha} \mathbf{( \mathbf { N ~ m ~ m }}{ }^{-1} \mathbf{M H z}^{-1}\right)$ & $\beta$ \\
\hline Water & 1000 & 1500 & $2.88 \times 10^{-4}$ & 3.5 \\
Liver & 1036 & 1596 & 3.5 & 5 \\
\hline
\end{tabular}

Table 2. Values of thermal parameters in this study $\left(37^{\circ} \mathrm{C}\right)$.

\begin{tabular}{|c|c|c|c|}
\hline Material & $K\left(\mathbf{W} \mathbf{m}^{-1 \circ} \mathrm{C}^{-1}\right)$ & $C\left(\mathrm{~J} \mathrm{Kg}^{-1}{ }^{\circ} \mathrm{C}^{-1}\right)$ & $W_{b}\left(\mathrm{Kg} \mathrm{m}^{-3} \mathrm{~s}^{-1}\right)$ \\
\hline Water & 0.6 & 4180 & 0 \\
\hline Liver & 0.5 & 3560 & 18.2 \\
\hline
\end{tabular}

\subsection{Description of the Simulation}

The HIFU transducer is a spherical cap with an aperture radius $a$ of $35 \mathrm{~mm}$, a focal length $F$ of $62.64 \mathrm{~mm}$, and a center frequency $f$ of $1 \mathrm{MHz}$. The transducer and liver tissue are placed in the water at $37^{\circ} \mathrm{C}$, and a geometric configuration of the physical model is shown in Figure 2 .

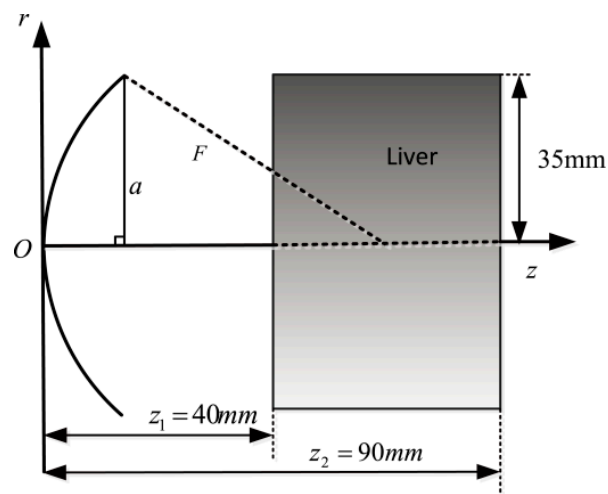

Figure 2. Geometric configuration of the physical model. The liver tissue is a cylinder with a radius of $35 \mathrm{~mm}$ and a length of $50 \mathrm{~mm}$, and is placed at $z_{1}=40 \mathrm{~mm}$.

As the tissue temperature rises, the tissue properties also change dynamically. These tissue properties need to be updated in real time according to the temperature, and the updated tissue properties are fed back into the calculation of the acoustic field and temperature field. The flowchart in Figure 3 shows how to carry out the coupling calculation of the acoustic and temperature field under such dynamic conditions. The acoustic field and temperature field are coupled by the heat deposition term $Q_{\text {ext }}$, which is computed from the acoustic pressure. In the practical simulation, the temperature field is calculated periodically, and the resulting temperature data is used to renew the tissue properties 
using the function above at each spatial point on the tissue domain. The updated tissue properties are then used as an input to recalculate the acoustic field. Therefore, the acoustic field, temperature field, and tissue properties are mutually influenced. In this study, the acoustic parameters and acoustic field are updated for the simulations here every $1 \mathrm{~s}$ unless otherwise noted, and the thermal parameters are updated in real time. This coupling method is based on the time rates of change of the tissue properties being slow enough in the given period interval.

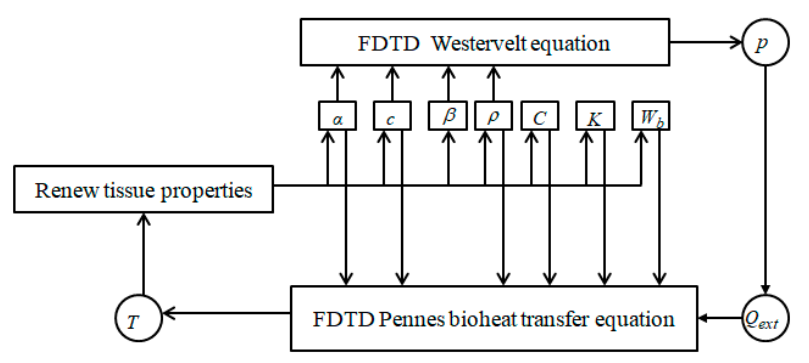

Figure 3. Flowchart of the iterative method for coupling acoustic pressure and temperature calculation.

For this study, the acoustic field and temperature field are calculated on a polar cylindrical grid using the explicit finite-difference time-domain (FDTD) method as described by Hallaj [26]. The spatial grids for the simulation are: $\Delta z=\Delta r=10^{-4} \mathrm{~m}$. The time step for the acoustic field and temperature field simulation are $10^{-8} \mathrm{~s}$ and $0.01 \mathrm{~s}$, respectively [26]. All of the simulations are performed with MATLAB programming based on the FDTD method.

\section{Result and Discussion}

In this manuscript, we focus on the effect of each dynamic tissue property independent from each other, and compared these effects with the conventional method of keeping the tissue properties as constant. When the effect of one dynamic tissue property is studied, the other tissue properties remain constant unless otherwise noted. In the following study, the amplitude of acoustic pressure on the sound source face $p_{0}$ is $1.4 \times 10^{5} \mathrm{~Pa}$ unless otherwise noted.

\subsection{Dynamic Acoustic Absorption Coefficient}

Simulations are carried out that only consider the change of the acoustic absorption coefficient with temperature independently. To get more accurate simulation results, the acoustic absorption coefficient and acoustic field are updated here every $0.2 \mathrm{~s}$. Figure 4a depicts the axial profile of the acoustic absorption coefficient during $3 \mathrm{~s}$ of HIFU irradiation. The acoustic absorption coefficient near ultrasonic focus increases with the time of HIFU irradiation. At time $t=3 \mathrm{~s}$, Figure $4 \mathrm{~b}$ illustrates the axial distribution of peak acoustic pressure. Clearly, the peak acoustic pressures are almost the same between dynamic $\alpha_{\text {liver }}$ and constant $\alpha_{\text {liver }}$. It can be explained that the temperature only has a great effect on the acoustic absorption coefficient near the ultrasonic focus, as shown in Figure 4a. In Figure $4 \mathrm{c}$, the maximum value of $Q_{\text {ext }}$ is $8.938 \times 10^{7} \mathrm{~W} / \mathrm{m}^{2}$ for constant $\alpha_{\text {liver }}$, and $2.179 \times 10^{8} \mathrm{~W} / \mathrm{m}^{2}$ for dynamic $\alpha_{\text {liver }}$. The features can be explained that $Q_{\text {ext }}$ is proportional to the acoustic absorption coefficient, according to Formula (5). Figure $4 \mathrm{~d}$ contrasts the evolution of the focal temperature with time for dynamic and constant $\alpha_{\text {liver }}$. Before $t=1 \mathrm{~s}$, the rate of the focal temperature rise is almost the same for simulations using dynamic $\alpha_{\text {liver }}$ and constant $\alpha_{\text {liver }}$. This may be due to the small change of the acoustic absorption coefficient during the early HIFU irradiation stage, as shown in Figure 4a. After $\mathrm{t}=1 \mathrm{~s}$, the focal temperature for dynamic $\alpha_{\text {liver }}$ rises much faster than that for constant $\alpha_{\text {liver }}$. When $\mathrm{t}=3 \mathrm{~s}$, the focal temperature is $65.94{ }^{\circ} \mathrm{C}$ for constant $\alpha_{\text {liver }}$ and $85.53^{\circ} \mathrm{C}$ for dynamic $\alpha_{\text {liver }}$. Figure $4 \mathrm{e}$ plots the shape of the thermal damage zone, representing the heated region for more than 240 min equivalent time at $43^{\circ} \mathrm{C}$. The thermal damage zone is an ellipse of $0.51 \mathrm{~cm} \times 0.12 \mathrm{~cm}$ size for constant $\alpha_{\text {liver }}$, and an ellipse of $0.6 \mathrm{~cm} \times 0.16 \mathrm{~cm}$ size for dynamic $\alpha_{\text {liver }}$. These phenomena indicate that dynamic $\alpha_{\text {liver }}$ has a greater effect on the focal temperature and thermal damage zone as the 
HIFU irradiation time increases, compared with constant $\alpha_{\text {liver }}$, which can be explained by the greater acoustic absorption coefficient being related to a greater the value of $Q_{\text {ext }}$, higher focal temperature, and larger thermal damage zone. Figure $4 \mathrm{f}$ describes the axial profile of the thermal dose, and the black dotted line denotes the value $\log _{10}(240) \mathrm{min}$. The axial length $\mathrm{AB}$ of the thermal damage zone is $0.51 \mathrm{~cm}$ for constant $\alpha_{\text {liver }}$, and the axial length CD of the thermal damage zone is $0.6 \mathrm{~cm}$ for dynamic $\alpha_{\text {liver }}$, which are consistent with the axial length of thermal damage zone in Figure 4e. Meanwhile, the thermal dose of ultrasonic focus for dynamic $\alpha_{\text {liver }}$ is much greater than that for constant $\alpha_{\text {liver }}$.
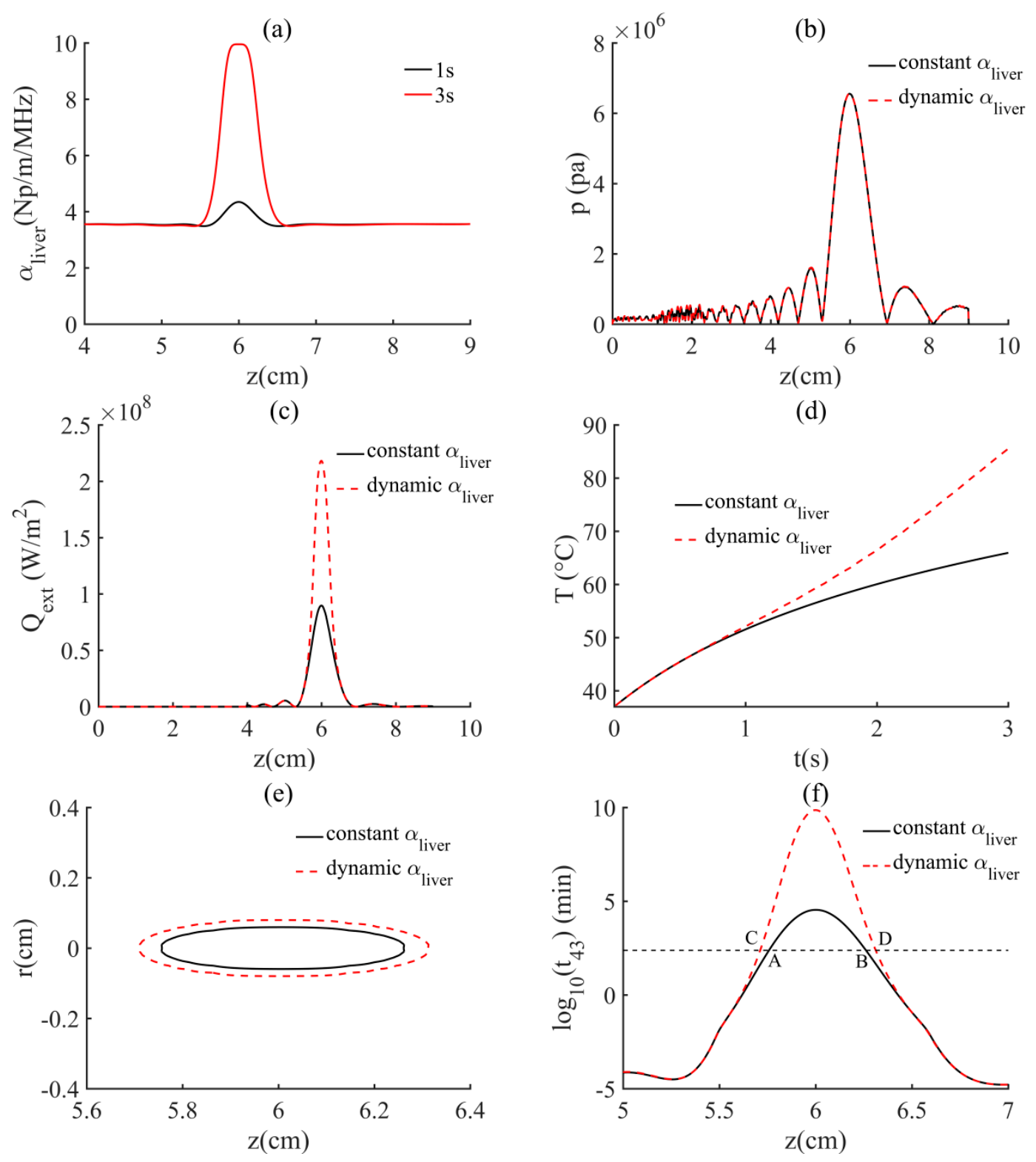

Figure 4. (a) The evolution of $\alpha_{\text {liver }}$ at $\mathrm{t}=1 \mathrm{~s}$ and $3 \mathrm{~s}$. The effects of the dynamic acoustic absorption coefficient on: (b) $p$ (c) $Q_{\text {ext }}(\mathbf{d}) T$ at the ultrasonic focus (e) thermal damage zone (f) $t_{43}$ at $\mathrm{t}=3 \mathrm{~s}$.

\subsection{Dynamic Non-linearity Parameter}

Simulation is carried out considering the change of the non-linearity parameter with temperature independently. The HIFU irradiation time is set to $5 \mathrm{~s}$ to ensure the validity of the dynamic non-linearity parameter used in the range of $30^{\circ} \mathrm{C}$ to $75^{\circ} \mathrm{C}$, and the non-linearity parameter and acoustic field are updated here every $0.5 \mathrm{~s}$. In Figure $5 \mathrm{~b}$, the axial profile of peak acoustic pressure at $5 \mathrm{~s}$ is almost identical for dynamic and constant $(B / A)_{\text {liver }}$. This phenomenon can be attributed to the local increase 
of the non-linearity parameter near the ultrasonic focus with the increase of HIFU irradiation time, as shown in Figure 5a. According to Formula (5), the value of $Q_{\text {ext }}$ for dynamic $(B / A)_{\text {liver }}$ is almost the same as that for constant $(B / A)_{\text {liver }}$. Consequently, the change of the focal temperature with time and the thermal damage zone are almost identical for dynamic and constant $(B / A)_{\text {liver }}$, as shown in Figure $5 c$,d. It can be concluded that the dynamic acoustic non-linear parameter has little effect on the HIFU hyperthermia.
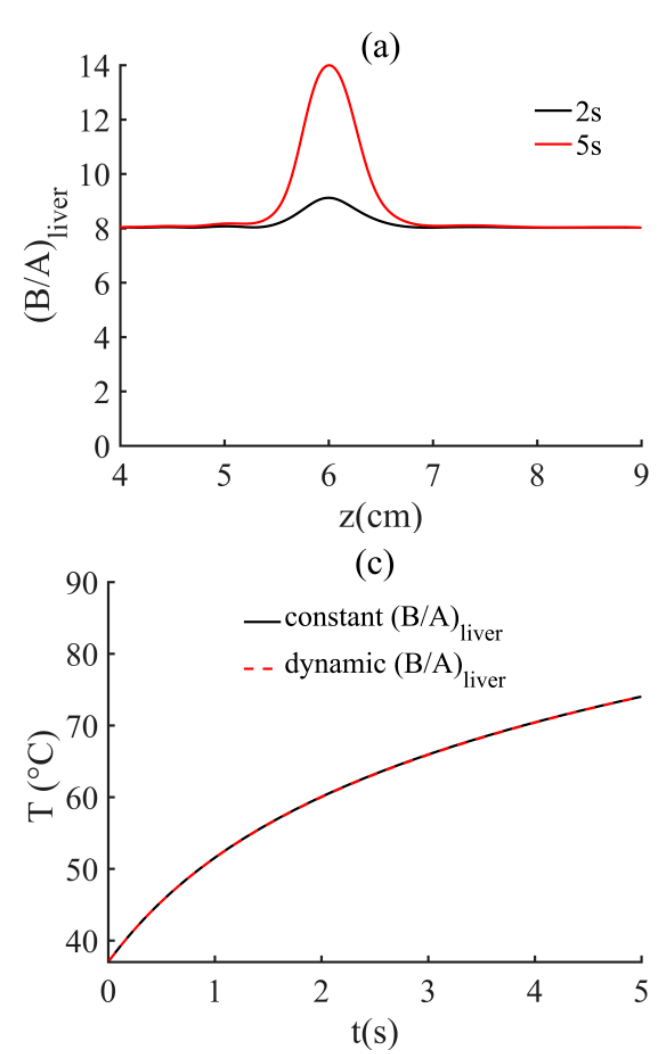

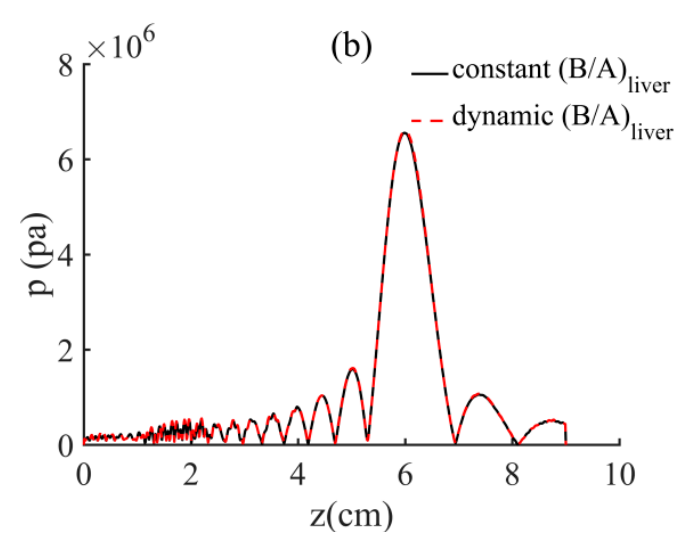

(d)

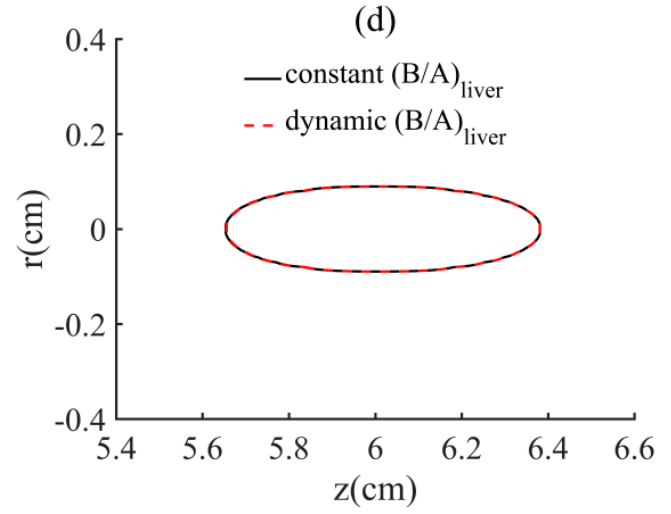

Figure 5. (a) The evolution of $(B / A)_{\text {liver }}$ at $\mathrm{t}=2 \mathrm{~s}$ and $5 \mathrm{~s}$. The effects of the dynamic non-linearity parameter on: (b) $p$ and (c) $T$ at the ultrasonic focus, and (d) the thermal damage zone at $t=5 \mathrm{~s}$.

\subsection{Dynamic Sound Speed, Specific Heat Capacity, Thermal Conductivity, and Density}

Simulations are carried out using the dynamic sound speed, dynamic specific heat capacity, dynamic thermal conductivity, and dynamic density, respectively, and the HIFU irradiation time is $10 \mathrm{~s}$. Figure 6 describes the axial profiles of dynamic sound speed, dynamic specific heat capacity, dynamic thermal conductivity, and dynamic density, which are affected only by the temperature in the vicinity of the ultrasonic focus. 


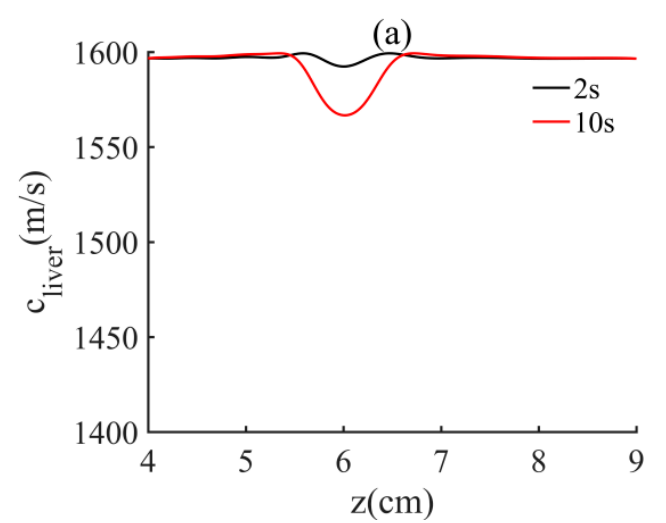

(c)

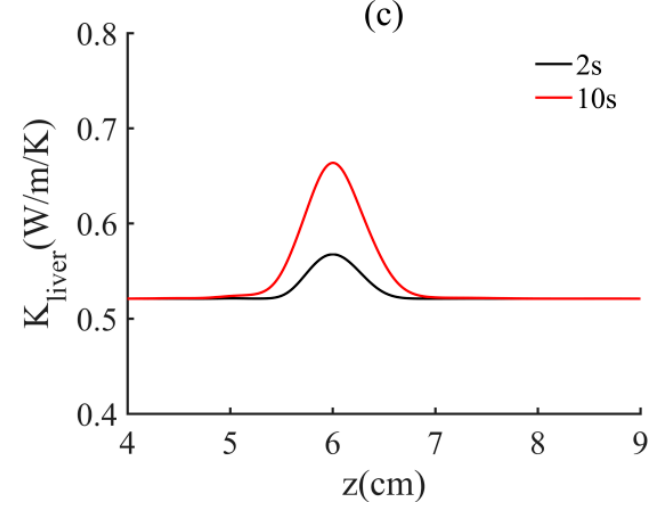

(b)

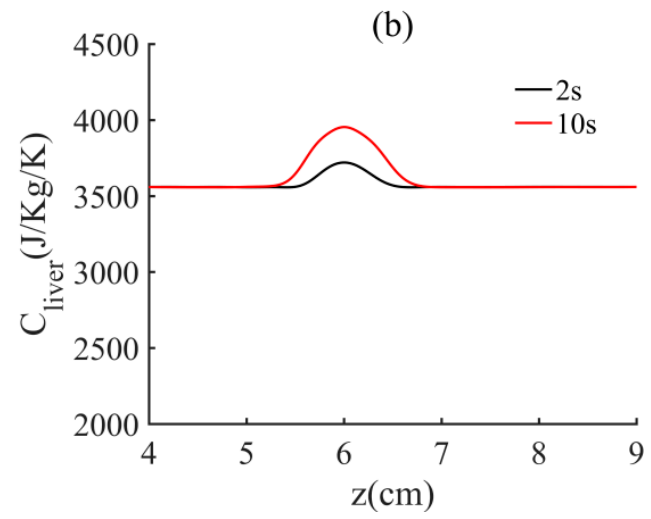

(d)

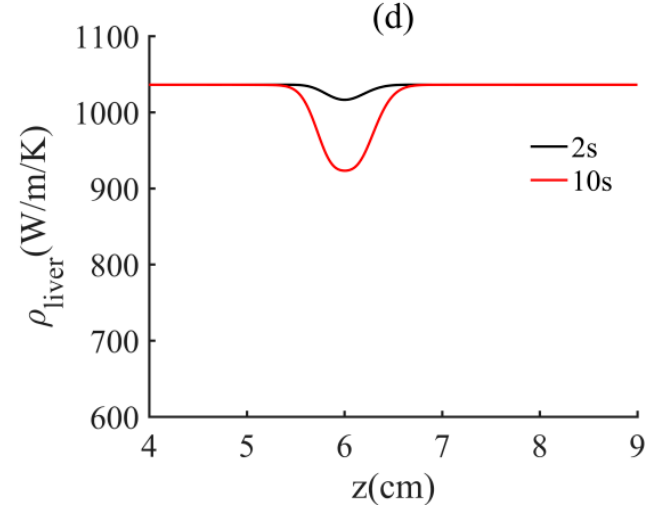

Figure 6. The axial profiles of (a) $c_{\text {liver }}(\mathbf{b}) C_{\text {liver }}(\mathbf{c}) K_{\text {liver }}$, and (d) $\rho_{\text {liver }}$ at $\mathrm{t}=2 \mathrm{~s}$ and $10 \mathrm{~s}$.

Figure 7a shows that the axial profiles of the peak acoustic pressure for simulations with dynamic $C_{\text {liver }}$, dynamic $K_{\text {liver, }}$, and dynamic $\rho_{\text {liver }}$ are almost the same as that for simulation with constant tissue properties. At ultrasonic focus, the peak acoustic pressure with dynamic $c_{\text {liver }}$ is a little greater than that with constant tissue properties, which is consistent with previously reported results [14]. Figure $7 \mathrm{~b}$ demonstrates the evolutions of focal temperature with time for simulations using dynamic $c_{\text {liver }}$, dynamic $C_{\text {liver }}$, dynamic $K_{\text {liver }}$, dynamic $\rho_{\text {liver }}$, and constant tissue properties, respectively. Before $t=2 \mathrm{~s}$, the rate of focal temperature rise is almost the same for simulations using dynamic $c_{\text {liver, }}$, dynamic $C_{\text {liver }}$, dynamic $K_{\text {liver }}$, dynamic $\rho_{\text {liver }}$, and constant tissue properties. This may be due to the very small change in the tissue properties during the early HIFU irradiation stage, as shown in Figure 6 . After $t=2 \mathrm{~s}$, Figure 6 shows that the sound speed and density decrease with the increase of HIFU irradiation time, but the specific heat capacity and thermal conductivity have the opposite trend. According to Formula (5), the values of focal $Q_{\text {ext }}$ for dynamic $c_{\text {liver }}$ and dynamic $\rho_{\text {liver }}$ are both greater than that for the constant tissue properties. Consequently, the rate of focal temperature rise for dynamic $c_{\text {liver }}$ and dynamic $\rho_{\text {liver }}$ is faster than that for constant tissue properties, as shown in Figure $7 \mathrm{~b}$. The rate of focal temperature rise for dynamic $C_{\text {liver }}$ is slower than that for constant tissue properties. This feature can be explained by the physical significance of specific heat capacity, which is defined as the amount of energy that is required to increase the temperature of a unit mass of tissue by $1{ }^{\circ} \mathrm{C}$ [27]. In other words, for the same amount of heat energy and mass, the larger the specific heat capacity, the smaller the temperature rise. The focal temperature for dynamic $K_{\text {liver }}$ rises slower than that for constant $K_{\text {liver }}$, and the focal temperature for dynamic $K_{\text {liver }}$ is $5.33{ }^{\circ} \mathrm{C}$ lower than that for the constant tissue properties at $10 \mathrm{~s}$. This feature can be explained by the greater thermal conductivity meaning that more thermal energy is lost from the treated areas because of thermal diffusion [28]. Therefore, it can be concluded that greater thermal conductivity leads to a slower focal temperature rise, which is similar to Guntur's result [9]. The maximum focal temperatures for simulations using dynamic $c_{\text {liver }}$, dynamic $C_{\text {liver }}$, dynamic $\rho_{\text {liver }}$, and constant tissue properties are $86.66^{\circ} \mathrm{C}, 84.58^{\circ} \mathrm{C}, 88.62{ }^{\circ} \mathrm{C}$, and $85.47^{\circ} \mathrm{C}$, respectively, indicating that dynamic $c_{\text {liver }}$, dynamic $C_{\text {liver }}$, 
and dynamic $\rho_{\text {liver }}$ have little effect on the temperature during HIFU hyperthermia. This is mainly due to the local variations of tissue property near the ultrasonic focus. Figure $7 \mathrm{c}$ shows that the thermal damage zones for dynamic $c_{\text {liver }}$, dynamic $C_{\text {liver }}$, dynamic $K_{\text {liver }}$, dynamic $\rho_{\text {liver }}$, and constant tissue properties are almost the same, which can also be confirmed from Figure $7 \mathrm{~d}$. It's interesting to note that the maximum focal temperature for dynamic $K_{\text {liver }}$ is lower than that for constant $K_{\text {liver }}$, but the thermal damage zone is almost the same for dynamic $K_{\text {liver }}$ and constant $K_{\text {liver }}$. It is mainly because the size of the thermal damage zone depends on the thermal dose above $240 \mathrm{~min}$ at $43^{\circ} \mathrm{C}$, rather than the maximum focal temperature.
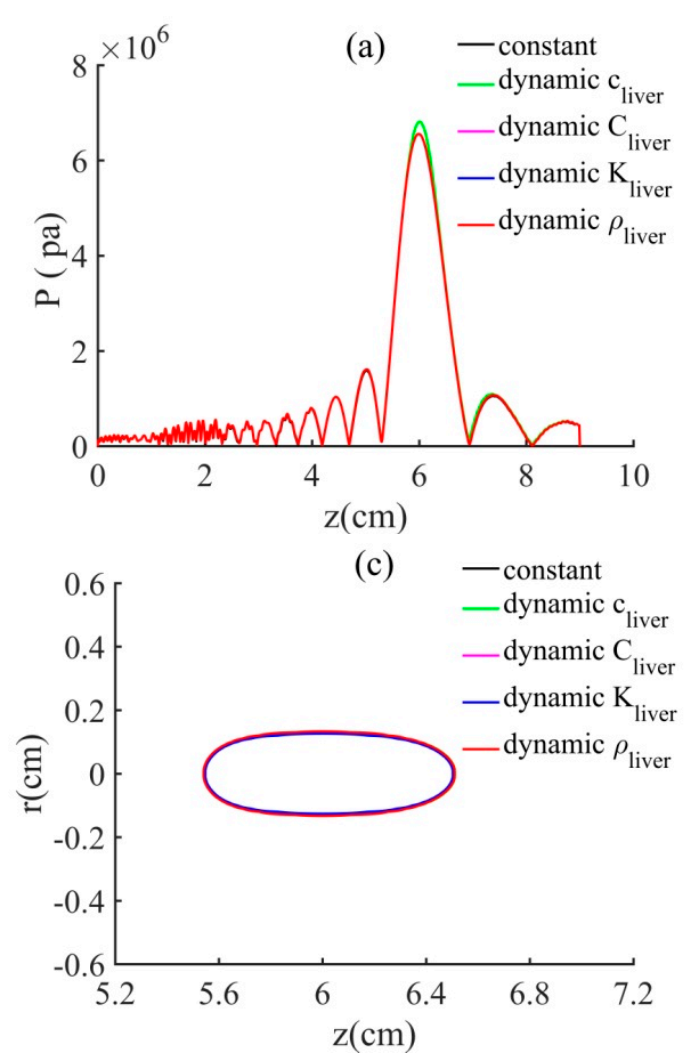

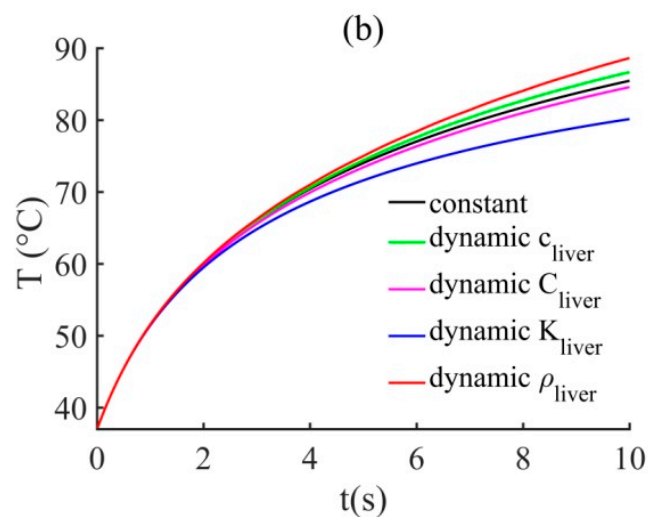

(d)

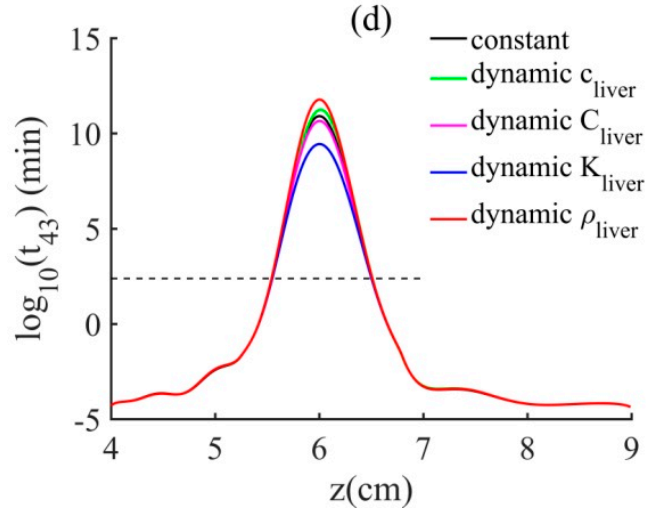

Figure 7. The effects of dynamic sound speed, dynamic specific heat capacity, dynamic thermal conductivity, and dynamic density on: (a) $p$ and (b) $T$ at the ultrasonic focus, (c) the thermal damage zone, and (d) $t_{43}$ at $\mathrm{t}=10 \mathrm{~s}$.

\subsection{Dynamic Blood Perfusion}

The simulation is performed only considering the dynamic change of blood perfusion, and the HIFU irradiation time is $10 \mathrm{~s}$. The blood perfusion firstly increased, then remained unchanged, and finally decreased to zero as shown in Figure 8a. This is because the initial increase in temperature causes the blood vessels to inflate to increase blood perfusion. As the temperature continues to increase, the tissue damage fraction increases so that the blood perfusion decreases. When the tissue undergoes coagulation necrosis, the blood perfusion decreases to zero. Figure $8 \mathrm{~b}$ describes the axial profile of dynamic blood perfusion at $\mathrm{t}=2 \mathrm{~s}$ and $10 \mathrm{~s}$. Compared with other tissue properties, the temperature has a greater impact on the blood perfusion of the surrounding tissue around the central axis. At time $t=10 \mathrm{~s}$, the axial profile of the peak acoustic pressure for dynamic $W_{b, l i v e r}$ is almost the same as that for the constant $W_{b \text {,liver }}$, as shown in Figure 8c. In Figure 8d, the temperature rise for dynamic $W_{b, l i v e r}$ is slower at first; then, it is faster than that for the constant $W_{b, l i v e r}$. It is because blood perfusion is first increased to four times the constant blood perfusion, and then remains unchanged, and is finally reduced to zero, as shown in Figure 8a. Figure 8e shows that the thermal damage zone is an ellipse of $0.97 \mathrm{~cm} \times 0.26 \mathrm{~cm}$ size for constant $W_{b, \text { liver }}$ and an ellipse of $0.89 \mathrm{~cm} \times 0.24 \mathrm{~cm}$ size for dynamic $W_{b, l i v e r}$, 
respectively. Thus, it can be seen that the thermal damage zone for dynamic $W_{b, l i v e r}$ is smaller than that for constant $W_{b, l i v e r}$, which can also be verified by the axial thermal dose distribution of Figure $8 f$.
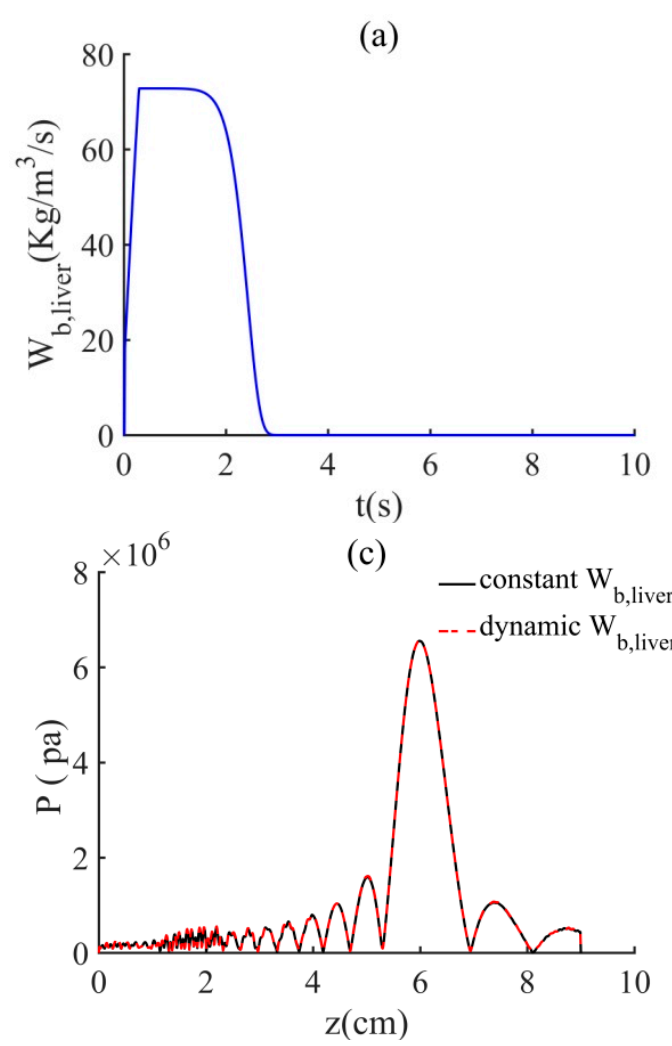

(e)

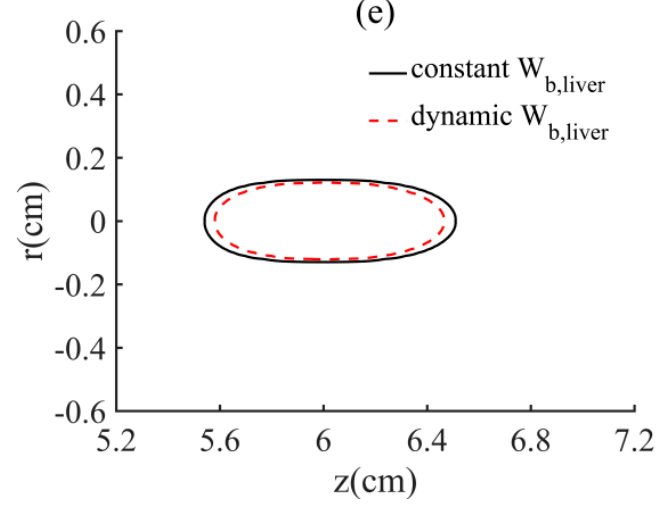

(b)

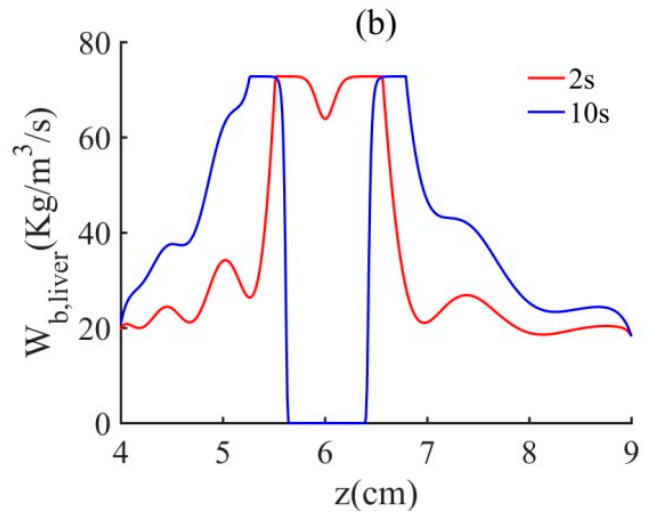

(d)

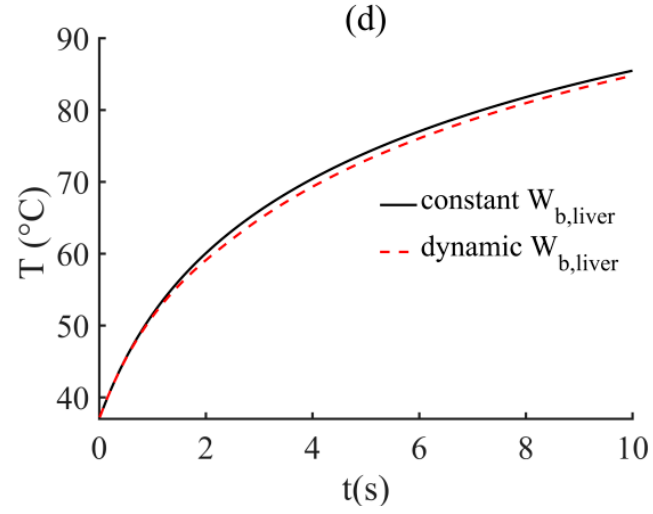

(f)

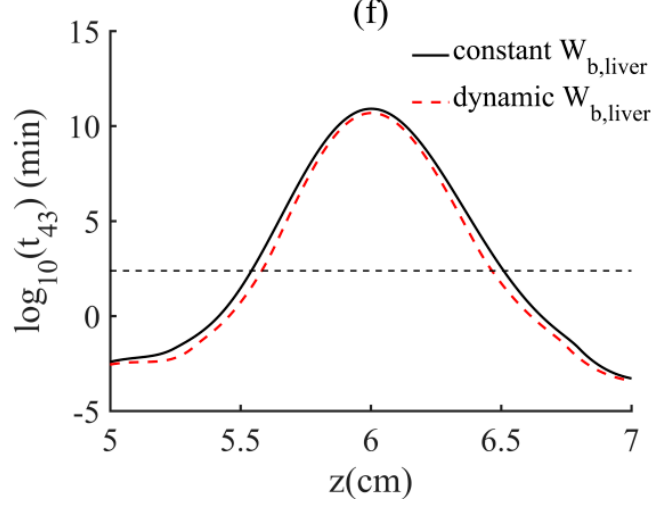

Figure 8. (a) Dynamic blood perfusion change with time. (b) Axial profile of dynamic blood perfusion at $\mathrm{t}=2 \mathrm{~s}$ and $10 \mathrm{~s}$. The effects of dynamic blood perfusion on: (c) $p$ and (d) $T$ at the ultrasonic focus and (e) thermal damage zone; (f) $Q_{43}$ at $\mathrm{t}=10 \mathrm{~s}$.

\subsection{Considering All Dynamic Tissue Properties}

In the above research results, the individual influence of each tissue property on HIFU hyperthermia was studied independently. Therefore, in this section, it is necessary to perform the simulation using all of the dynamic tissue properties to explore the joint influence on HIFU hyperthermia by comparing them with simulations using dynamic $\alpha_{l i v e r}$ and constant tissue properties. Note that we assume that the non-linearity parameter above $75^{\circ} \mathrm{C}$ is replaced by that at $75{ }^{\circ} \mathrm{C}$ to simplify the physical model owing to (i) the dynamic non-linear parameter being found to have little effect on the acoustic pressure, temperature, and thermal damage zone in our calculation (Figure $5 \mathrm{~b}-\mathrm{d}$ ); and (ii) above $75^{\circ} \mathrm{C}$, biological tissue having been coagulated. To ensure that all of the dynamic tissue properties are valid within their respective temperature ranges, the HIFU irradiation time is set to 
$3 \mathrm{~s}$. At time $\mathrm{t}=3 \mathrm{~s}$, Figure 9a shows that the peak acoustic pressure for simulation using all of the dynamic tissue properties is larger than that using dynamic $\alpha_{\text {liver }}$ and constant tissue properties due to the influence of dynamic sound velocity, and the peak acoustic pressures are almost the same between the dynamic $\alpha_{\text {liver }}$ and constant tissue properties. In Figure $9 \mathrm{~b}$, the peak value of $Q_{\text {ext }}$ is the greatest for simulation using all of the dynamic tissue properties, followed by that for simulation using dynamic $\alpha_{\text {liver, }}$, and the smallest for simulation using constant tissue properties. In Figure $9 \mathrm{c}$, before $t=1 \mathrm{~s}$, the focal temperature is almost the same for simulation using dynamic $\alpha_{\text {liver }}$ across all of the dynamic tissue properties and constant tissue properties; after $t=1 \mathrm{~s}$, the rate of focal temperature rise is fastest for simulation using dynamic $\alpha_{\text {liver }}$, followed by that for simulation using all of the dynamic tissue properties, and slowest for simulation using constant tissue properties. The maximum focal temperature for all of the dynamic tissue properties, dynamic $\alpha_{\text {liver }}$, and constant tissue properties are $81.56{ }^{\circ} \mathrm{C}, 85.53{ }^{\circ} \mathrm{C}$, and $65.94{ }^{\circ} \mathrm{C}$, respectively, indicating that the maximum focal temperature for all of the dynamic tissue properties is lower than that for dynamic $\alpha_{\text {liver }}$, although the peak value of $Q_{\text {ext }}$ for all of the dynamic tissue properties is greater than that for dynamic $\alpha_{\text {liver }}$. Based on the above research, this is mainly due to the influence of the comprehensive factors such as dynamic $C_{\text {liver }}$, dynamic $K_{\text {liver }}$, and dynamic $W_{b, l i v e r}$ on focal temperature, especially the influence of dynamic $K_{\text {liver }}$. In Figure $9 \mathrm{~d}$, the thermal damage zone is an ellipse of $0.57 \mathrm{~cm} \times 0.16 \mathrm{~cm}$ size for all of the dynamic tissue properties, an ellipse of $0.6 \mathrm{~cm} \times 0.16 \mathrm{~cm}$ size for dynamic $\alpha_{\text {liver }}$, and an ellipse of $0.51 \mathrm{~cm} \times 0.12 \mathrm{~cm}$ size for constant tissue properties, respectively. Consequently, it is can be concluded that the simulation using constant tissue properties significantly underestimates the focal temperature and thermal damage zone compared with the simulation using all of the dynamic tissue properties or dynamic $\alpha_{\text {liver }}$. Meanwhile, although the dynamic acoustic absorption coefficient plays the most important role in relation to the focal temperature and thermal damage zone, other dynamic tissue properties ought to be considered.

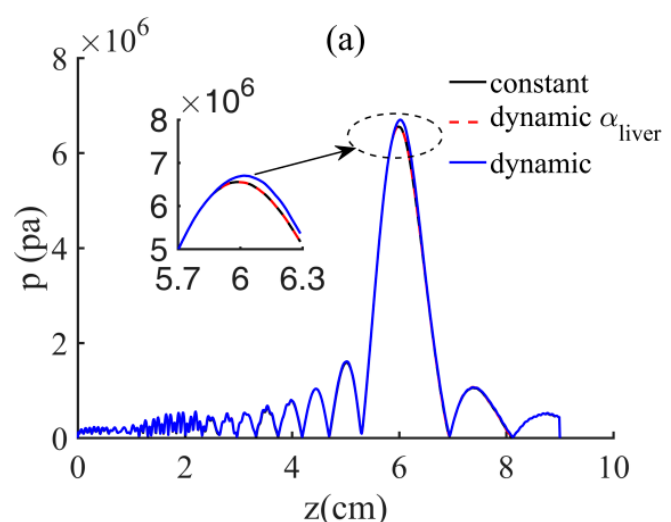

(c)

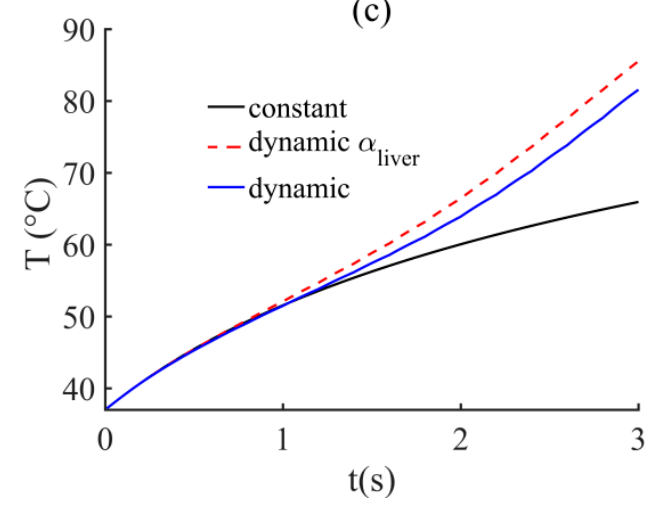

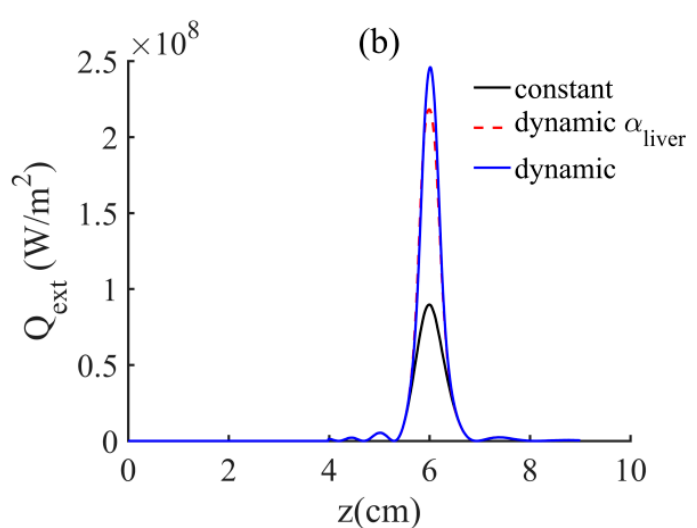

(d)

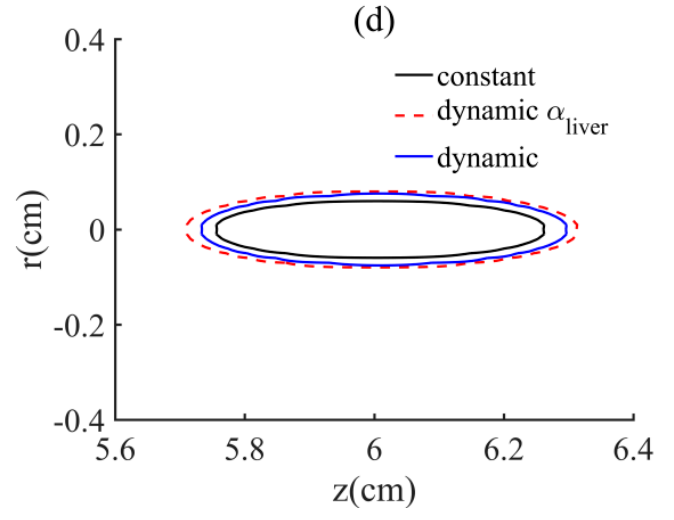

Figure 9. The effects of all of the dynamic tissue properties on: (a) $p$, (b) $Q_{\text {ext }}$, (c) $T$ at the ultrasonic focus, and (d) thermal damage zone. 


\section{Conclusions}

The influence of each dynamic tissue property on HIFU hyperthermia is studied independently based on the reported experimental data of dynamic tissue properties. The findings in the present study suggest that the acoustic pressure is insensitive to the dynamic tissue properties. The numerical results also show that the dynamic acoustic absorption coefficient significantly affects the temperature and thermal damage zone; on the contrary, the dynamic non-linearity parameter has almost no effect on the temperature and thermal damage zone. It is found that the thermal damage zone for dynamic $W_{b, l i v e r}$ is smaller than that for constant $W_{b, l i v e r}$, and the influence of a dynamic sound speed, dynamic specific heat capacity, and dynamic density on the thermal damage zone is slight. It is also worth mentioning that the maximum focal temperature for dynamic $K_{\text {liver }}$ is lower than that for constant $K_{\text {liver }}$, but the thermal damage zone is almost the same for dynamic $K_{\text {liver }}$ and constant $K_{\text {liver }}$. Among all of the individual dynamic tissue properties, the dynamic acoustic absorption coefficient has the greatest influence on the temperature and thermal damage zone. Knowing the influence of each dynamic tissue property is beneficial to our deep understanding of the principle of HIFU therapy. Besides studying the influence of each individual dynamic tissue property, the simulation considering all of the dynamic tissue properties to explore the comprehensive influence on HIFU hyperthermia is performed. The numerical results show that the maximum focal temperature and thermal damage zone for simulation using all of the dynamic tissue properties increase, compared with those for simulation using constant tissue properties, implying that the simulation using constant tissue properties underestimates the focal temperature and thermal damage zone compared with the simulation using all of the dynamic tissue properties. Moreover, it is interesting to point out that the thermal energy absorbed by the tissue for simulation using all of the dynamic tissue properties is greater than that for simulation using dynamic $\alpha_{\text {liver }}$, but the maximum focal temperature and thermal damage zone for simulation using all of the dynamic tissue properties decrease, compared with those for simulation using dynamic $\alpha_{\text {liver }}$. Consequently, when doctors develop a more accurate clinical protocol for HIFU treatment planning, it is necessary to consider all of the dynamic tissue properties to assess the size of thermal damage zone, so as not to damage normal tissue.

Author Contributions: S.Q. conceived and designed the research idea and the framework; Q.T. and X.Z. (Xiao Zou) performed the simulations; Q.T. and X.Z. (Xiao Zou) wrote the paper; S.Q., Q.T. and Y.D. analyzed the data, S.Q. and X.Z. (Xinmin Zhao) modified the paper.

Acknowledgments: This work is partially supported by the National Nature Science Foundation of China (No. 11474090, 11774088, 11174077, 61502164), Hunan Provincial Natural Science Foundation of China (No. 2016JJ3090), Scientific Research Fund of Hunan Provincial Education Department (No. 16B155), Aid program for Science and Technology Innovative Research Team in Higher Educational Institutions of Hunan Province, Science and Technology Research Program of Chenzhou City (No. CZ2014039) and Research Program of Xiangnan University (No. 2014XJ63).

Conflicts of Interest: The authors declare no conflict of interest.

\section{References}

1. Chen, W.; Sun, K.; Zheng, R.; Zeng, H.; Zhang, S.; Xia, C.; Yang, Z.; Li, H.; Zou, X.; He, J. Cancer incidence and mortality in China, 2014. Chin. J. Cancer Res. 2018, 30, 1-12. [CrossRef] [PubMed]

2. Cranston, D. A review of high intensity focused ultrasound in relation to the treatment of renal tumours and other malignancies. Ultrason. Sonochem. 2015, 27, 654-658. [CrossRef] [PubMed]

3. Manthe, R.L.; Foy, S.P.; Krishnamurthy, N.; Sharma, B.; Labhasetwar, V. Tumor Ablation and Nanotechnology. Mol. Pharm. 2010, 7, 1880-1898. [CrossRef] [PubMed]

4. Zhou, Y. Acoustic power measurement of high-intensity focused ultrasound transducer using a pressure sensor. Med. Eng. Phys. 2015, 37, 335-340. [CrossRef] [PubMed]

5. Xiao, J.; Sun, T.; Zhang, S.; Ma, M.; Yang, X.; Zhou, J.; Zhu, J.; Wang, F. HIFU, a noninvasive and effective treatment for chyluria: 15 years of experience. Surg. Endosc. 2018, 32, 3064-3069. [CrossRef] [PubMed] 
6. Nover, A.B.; Hou, G.Y.; Han, Y.; Wang, S.; O'Connell, G.D.; Ateshian, G.A.; Konofagou, E.E.; Hung, C.T. High intensity focused ultrasound as a tool for tissue engineering: Application to cartilage. Med. Eng. Phys. 2016, 38, 192-198. [CrossRef] [PubMed]

7. Huang, C.W.; Sun, M.K.; Chen, B.T.; Shieh, J.; Chen, C.S.; Chen, W.S. Simulation of thermal ablation by high-intensity focused ultrasound with temperature-dependent properties. Ultrason. Sonochem. 2015, 27, 456-465. [CrossRef] [PubMed]

8. Qian, K.; Li, C.; Ni, Z.; Tu, J.; Guo, X.; Zhang, D. Uniform tissue lesion formation induced by high-intensity focused ultrasound along a spiral pathway. Ultrasonics 2017, 77, 38-46. [CrossRef] [PubMed]

9. Guntur, S.R.; Choi, M.J. Influence of Temperature-Dependent Thermal Parameters on Temperature Elevation of Tissue Exposed to High-Intensity Focused Ultrasound: Numerical Simulation. Ultrasound Med. Biol. 2015, 41, 806-813. [CrossRef] [PubMed]

10. Damianou, C.A.; Sanghvi, N.T.; Fry, F.J.; Maass-Moreno, R. Dependence of ultrasonic attenuation and absorption in dog soft tissues on temperature and thermal dose. J. Acoust. Soc. Am. 1997, 102, 628-634. [CrossRef] [PubMed]

11. Bamber, J.C.; Hill, C.R. Ultrasonic attenuation and propagation speed in mammalian tissues as a function of temperature. Ultrasound Med. Biol. 1979, 5, 149-157. [CrossRef]

12. Choi, M.J.; Guntur, S.R.; Lee, J.M.; Paeng, D.G.; Lee, K.I.L.; Coleman, A. Changes in Ultrasonic Properties of Liver Tissue In Vitro During Heating-Cooling Cycle Concomitant with Thermal Coagulation. Ultrasound Med. Biol. 2011, 37, 2000-2012. [CrossRef] [PubMed]

13. Guntur, S.R.; Lee, K.I.; Paeng, D.G.; Coleman, A.J.; Choi, M.J. Temperature-Dependent Thermal Properties of Ex Vivo Liver Undergoing Thermal Ablation. Ultrasound Med. Biol. 2013, 39, 1771-1784. [CrossRef] [PubMed]

14. Hallaj, I.M.; Cleveland, R.O.; Hynynen, K. Simulations of the thermo-acoustic lens effect during focused ultrasound surgery. J. Acoust. Soc. Am. 2001, 109, 2245-2253. [CrossRef] [PubMed]

15. Christopher, W.C.; Kullervo, H. Bio-acoustic thermal lensing and nonlinear propagation in focused ultrasound surgery using large focal spots: A parametric study. Phys. Med. Biol. 2002, 47, 1911-1928.

16. Doinikov, A.A.; Novell, A.; Calmon, P.; Bouakaz, A. Simulations and measurements of 3-D ultrasonic fields radiated by phased-array transducers using the westervelt equation. IEEE Trans. Ultrason. Ferroelectr. Freq. Control 2014, 61, 1470-1477. [CrossRef] [PubMed]

17. Solovchuk, M.A.; Sheu, T.W.H.; Thiriet, M.; Lin, W.L. On a computational study for investigating acoustic streaming and heating during focused ultrasound ablation of liver tumor. Appl. Therm. Eng. 2013, 56, 62-76. [CrossRef]

18. Liu, G.; Jayathilake, P.G.; Khoo, B.C. Perturbation method for the second-order nonlinear effect of focused acoustic field around a scatterer in an ideal fluid. Ultrasonics 2014, 54, 576-585. [CrossRef] [PubMed]

19. Mur, G. Absorbing Boundary Conditions for the Finite-Difference Approximation of the Time-Domain Electromagnetic-Field Equations. IEEE Trans. 1981, -23. [CrossRef]

20. Pennes, H.H. Analysis of tissue and arterial blood temperatures in the resting human forearm. J. Appl. Physiol. 1948, 1, 93-122. [CrossRef] [PubMed]

21. Sapareto, S.A.; Dewey, W.C. Thermal dose determination in cancer therapy. Int. J. Radiat. Oncol. 1984, 10, 787-800. [CrossRef]

22. Jiang, S.; Zhang, X. Effects of dynamic changes of tissue properties during laser-induced interstitial thermotherapy (LITT). Laser Med. Sci. 2005, 19, 197-202. [CrossRef] [PubMed]

23. Shibib, K.S.; Munshid, M.A.; Lateef, H.A. The effect of laser power, blood perfusion, thermal and optical properties of human liver tissue on thermal damage in LITT. Laser Med. Sci. 2017, 32, 2039-2046. [CrossRef] [PubMed]

24. Zhou, J.; Chen, J.K.; Zhang, Y. Simulation of Laser-Induced Thermotherapy Using a Dual-Reciprocity Boundary Element Model with Dynamic Tissue Properties. IEEE Trans. Biomed. Eng. 2010, 57, 238-245. [CrossRef] [PubMed]

25. London, R.A.; Glinsky, M.E.; Zimmerman, G.B.; Bailey, D.S.; Eder, D.C.; Jacques, S.L. Laser-tissue interaction modeling with LATIS. Appl. Opt. 1997, 36, 9068-9074. [CrossRef] [PubMed]

26. Hallaj, I.M.; Cleveland, R.O. FDTD simulation of finite-amplitude pressure and temperature fields for biomedical ultrasound. J. Acoust. Soc. Am. 1999, 105, L7-L12. [CrossRef] [PubMed] 
27. Yang, D.; Converse, M.C.; Mahvi, D.M.; Webster, J.G. Expanding the Bioheat Equation to Include Tissue Internal Water Evaporation During Heating. IEEE Trans. Biomed. Eng. 2007, 54, 1382-1388. [CrossRef] [PubMed]

28. Roggan, A.; Mueller, G.J. Two-dimensional computer simulations for real-time irradiation planning of laser-induced interstitial thermotherapy (LITT). In Medical Applications of Lasers II; International Society for Optics and Photonics: Lille, France, 1994; pp. 242-253. 